MATEC Web of Conferences 33, 04002 (2015)

DOI: $10.1051 /$ matec conf/ 20153304002

(C) Owned by the authors, published by EDP Sciences, 2015

\title{
Factors influencing martensite transitions in Fe-based shape memory alloys
}

\author{
Elena Mihalache ${ }^{1}$, Bogdan Pricop ${ }^{1}$, Marius-Gabriel Suru ${ }^{1}$, Nicoleta Monica Lohan ${ }^{1}$, Radu loachim Comăneci ${ }^{1}$, Bogdan \\ Istrate $^{1}$, Burak Özkal ${ }^{2}$ and Leandru-Gheorghe Bujoreanu ${ }^{\text {ia }}$ \\ ${ }^{1}$ Faculty of Materials Science and Engineering, "Gheorghe Asachi" Technical University of laşi, Blvd. D. Mangeron 61 A, 700050 laşi, \\ Romania \\ ${ }^{2}$ Particulate Materials Laboratory, Metallurgical and Materials Engineering Department, Istanbul Technical University, 34469 Maslak, \\ Istanbul, Turkey
}

\begin{abstract}
Fe-14Mn-6Si-9Cr-5Ni (mass \%) shape memory alloy (SMA) specimens were obtained by powder metallurgy in as-blended state (0_MA) and with particle volume fractions of 10 and $20 \% \mathrm{MA}$ 'd powders, respectively. After hot rolling and solution treatment, between 973 and $1373 \mathrm{~K}$, the specimens were pre-strained up to $4 \%$, on a tensile testing machine. The influences of: (i) MA'd fractions, (ii) solution treatment temperature and (iii) pre-straining degree were analysed by X-ray diffraction (XRD), optical (OM) and scanning electron (SEM) microscopy. In this purpose, the gauges of pre-strained specimens were cut and metallographically prepared. Dynamic mechanical analysis (DMA) was employed to emphasize the reverse transformation, during heating, of thermally induced martensite, obtained after solution treatment. The results proved that, as an effect of PM-MA processing, mechanical properties were improved, the amount of stress induced martensite increased and the reverse martensitic transformation was enhanced.
\end{abstract}

\section{Introduction}

After the first reports on Fe-Mn-Si Shape Memory Alloys (SMAs) single crystals, due to Sato et al., [1-3], Murakami et al. succeeded to obtain Fe-(28-34) Mn-(4$6,5) \mathrm{Si}$ (mass. \%, as all chemical compositions will be listed hereinafter) polycrystalline alloys with almost perfect Shape Memory Effect (SME) [4-6]. Later, aiming to improve corrosion resistance, Otsuka et al. added $\mathrm{Cr}$ and $\mathrm{Ni}$ thus contributing to the development of Fe-28Mn6Si-5Cr [7] and $\mathrm{Fe}-14 \mathrm{Mn}-6 \mathrm{Si}-9 \mathrm{Cr}-5 \mathrm{Ni}$ SMAs [8], which became of commercial use [9]. In the alloys based on ternary $\mathrm{Fe}-\mathrm{Mn}-\mathrm{Si}$ system, the mechanism of Shape Memory Effect (SME) consists in the thermally induced reversion to $\gamma$-face centred cubic (fcc) austenite of $\varepsilon$ hexagonal close packed (hcp) stress-induced martensite [10]. Besides $\varepsilon$-hcp, a second martensitic phase, $\alpha^{\prime}$-body centred cubic (bcc), can be thermally or stress-induced, at low $\mathrm{Mn}$ content or high deformation degrees [11]. It has been argued that $\varepsilon$-hcp SIM plates should be as narrow as possible, with a single variant orientation and should interact neither with each other nor with pre-existing thermally induced martensite [12].

All the above findings were obtained on specimens obtained by ingot metallurgy processing, comprising casting of molten alloys, multiple remelting operations, to achieve target chemical compositions and prolonged heat treatments, for chemical composition homogenization [13].

\footnotetext{
${ }^{\mathrm{a}}$ Corresponding author: lgbujor@tuiasi.ro
}

An alternative processing routine is represented by powder metallurgy (PM) which is able to control both chemical composition and grain size [14], when accompanied by mechanical alloying (MA) [15] and intense hot pressing [16].

By extending MA-time to 30 hours and by applying subsequent sintering, Saito et al. obtained $\mathrm{Fe}_{60} \mathrm{Mn}_{29} \mathrm{Si}_{11}$ alloys with the possibility to show SME [17]. More recently, Amini et al. reported "mechano-crystalyzation of an amorphous phase" in Fe-32Mn-6Si SMAs which were mechanically alloyed (MA'd) between 96 and 192 hours [18] and Saito et al. used MA and sintering to improve mechanical properties and performing SME in Fe-30Mn-6Si SMAs, in comparison with the alloys processed by ingot metallurgy [19]. Finally, Xu et al. performed comparative studies on forged and sintered Fe-28Mn-(1-4)Si alloys and concluded that the latter had considerably lower tensile strength due to the presence of porosities, which reduced the load-carrying capacity and caused stress concentration around the pores [20].

All above results refer to "high manganese $\mathrm{Fe}-\mathrm{Mn}-\mathrm{Si}$ SMAs", which are generally ternary. In a series of works on quintenary $\mathrm{Fe}-\mathrm{Mn}-\mathrm{Si}-\mathrm{Cr}-\mathrm{Ni} \mathrm{SMAs}$, a part of present authors reported the thermally induced reversion to $\gamma$-fcc austenite of $\alpha^{\prime}$-bcc stress induced martensite [21] the formation of which was favoured by mechanical cycling up to $4 \%$ maximum applied strains [22]. The substitution of a fraction of as blended powders with MA'd particles contributed to the reduction of surface oxidation [23] 
being associated with the presence of amorphous regions in PM-MA powder mixtures [24] of $\mathrm{Fe}-14 \mathrm{Mn}-6 \mathrm{Si}-9 \mathrm{Cr}-$ $5 \mathrm{Ni}$ SMAs. In solution treated state, mechanical alloying enabled the increase of $\alpha^{\prime}$-bcc martensite amount [25] but with a suitable combination of MA'd powder fraction and corresponding selection of the parameters for sintering, rolling and solution treatment [26] an increase of shape recovery degree was recently observed in Fe-14Mn-6Si9Cr-5Ni SMAs [27].

Based on the promising results, reported by some of present authors, on the influence of heat treatment temperature and pre-straining magnitude on the formation of stress induced martensite in ingot metallurgy Fe-MnSi-Cr-Ni SMA [28], the present paper aims to study the same aspects in a PM SMA by considering the effects of substituting various fractions of as-blended powders with MA'd ones.

\section{Experimental}

Starting elemental powders of Fe $(75 \mu \mathrm{m}, 99.5 \%$ purity, Alfa AesarTM), Mn (53 $\mu \mathrm{m}, 99.3 \%$ purity, Alfa AesarTM), Si (150 $\mu \mathrm{m}, 99.9 \%$ purity, Alfa AesarTM), Cr (5-7 $\mu \mathrm{m}$, Lab received) and Ni (3-5 $\mu \mathrm{m}, 99.9 \%$ purity, Alfa AesarTM) were used in the experimental studies. Powder mixture having $66 \mathrm{Fe}, 14 \mathrm{Mn}, 6 \mathrm{Si}, 9 \% \mathrm{Cr}$ and 5 Ni (mass. \%) was selected as target composition. After mixing, as blended powders were compacted by uniaxial cold pressing under $400 \mathrm{MPa}$ and sintered to $1423 \mathrm{~K}$ for $7.2 \mathrm{ks}$ [29].

The first group of specimens (0_MA) was obtained from as-blended powders, while the second (10_MA) and third (20_MA) groups comprised 10 vol. \% and 20 vol. $\%$ fractions of mechanically alloyed (MA) powders, respectively, obtained after high energy ball milling under argon atmosphere [30].

Hot rolling was further applied with a working speed of $23.4 \times 10^{-2} \mathrm{~m} \times \mathrm{s}^{-1}$, at $1370 \mathrm{~K}$, to increase the compactness degree of sintered specimens. "Dog-bone" configurations for tensile tests and rectangular specimens for dynamic mechanical analysis (DMA) were further cut by spark erosion and solution treated for $0.3 \mathrm{ks}$ at 973 , $1073,1173,1273$ or $1373 \mathrm{~K}$. The specimens were designated by their fraction of MA'd powder followed by solution treatment temperature in ${ }^{0} \mathrm{C}$ (e.g. 20_MA 1100 contains 20 vol. \% MA'd powder and was solution treated at $1373 \mathrm{~K}$ ). Apparent density was accurately determined by hydrostatic weighing [31] with an electronic scales. The following porosity degrees were obtained: $16.85 \%$ for $0 \_$MA; $8.03 \%$ for $10 \_$MA and $5.94 \%$ for 20_MA.

The gauge of one representative dog-bone specimen corresponding to each of the above solution treated and MA'd states, was cut, embedded into cold mounting resin and metallographically prepared by grinding, polishing and etching [32] before being analysed by optical (OM) and scanning electron microscopy (SEM) as well as Xray diffraction (XRD).

Dog-bone solution treated specimens were prestrained, according to ISO 6892-1:2009 standard, with different deformation degrees, by means of an INSTRON
3382 tensile testing machine, with a constant crosshead speed of $1 \mathrm{~mm} / \mathrm{min}$. After tension, specimen gauges were cut, prepared and analysed by OM, SEM and XRD respectively, as above mentioned.

OM micrographs were recorded on an OPTIKA XDS3 MET microscope equipped with OPTIKAM 4083.B5 microscopy digital USB camera and OPTIKAM B5 software. SEM observations were performed by means of a SEM-VEGA II LSH TESCAN microscope, coupled with an EDX - QUANTAX QX2 ROENTEC detector. $\mathrm{XRD}$ patterns were recorded on the significance region $2 \theta=30-100^{\circ}$, using an Expert PRO MPD diffractometer with $\mathrm{Cu} \mathrm{K} \mathrm{K}_{\alpha}$ radiation. Corresponding crystallographic databases were used for the identification of the three above mentioned metallographic phases, $\alpha$-bcc, $\gamma$-fcc and $\varepsilon$-hcp.

DMA tests were performed with rectangular solution treated specimens on a device type DMA 242 Artemis NETZSCH, with force and amplitude resolutions of 50 $\mu \mathrm{N}$ and $0.5 \mathrm{~nm}$, respectively, equipped with "three-point bending" specimen holder. Heating was applied from room temperature (RT) to 673, under $\mathrm{Ar}$ protective atmosphere, with a temperature variation rate of $5 \mathrm{~K} /$ min, at constant frequency, $1 \mathrm{~Hz}$ and amplitude of $20 \mu \mathrm{m}$. The results were recorded under the form of DMA thermograms illustrating the variation of storage modulus (E') and internal friction $(\tan \delta$ ) as a function of temperature.

\section{Experimental results and discussion}

Three series of tensile pre-straining curves, of the specimens with different fractions of MA'd powders subjected to 5 different solution treatments, are shown in Fig.1.

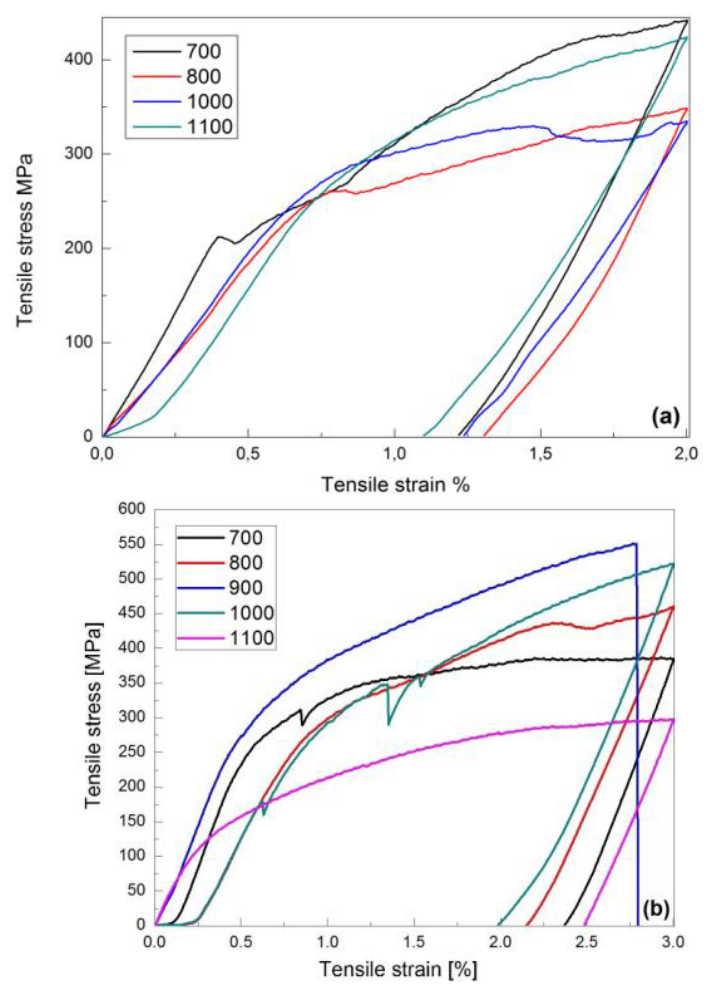




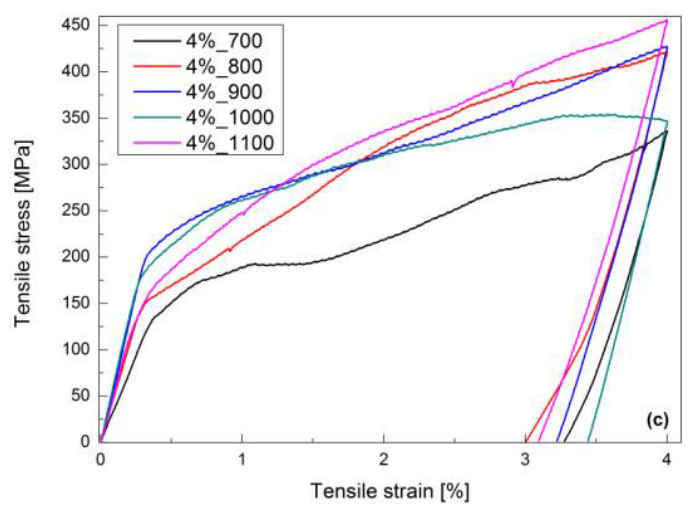

Figure 1. Tensile pre-straining curves of heat treated specimens: (a) 0_MA; (b) 10_MA; (c) 20_MA.

As expected, the presence of porosity enhanced brittleness. For this reason, maximum applied strain did not exceed $4 \%$. With few exceptions, the specimens behave similarly during unloading in such a way that the respective portions are parallel.

After unloading, cutting, embedding and metallographic preparation, the presence of stress induced martensite was emphasized on OM and SEM micrographs. Fig.2 illustrates a series of characteristic aspects of the specimens 0_MA, solution treated to the lowest, $973 \mathrm{~K}$ and highest, $1373 \mathrm{~K}$ temperatures, in initial and pre-strained condition.

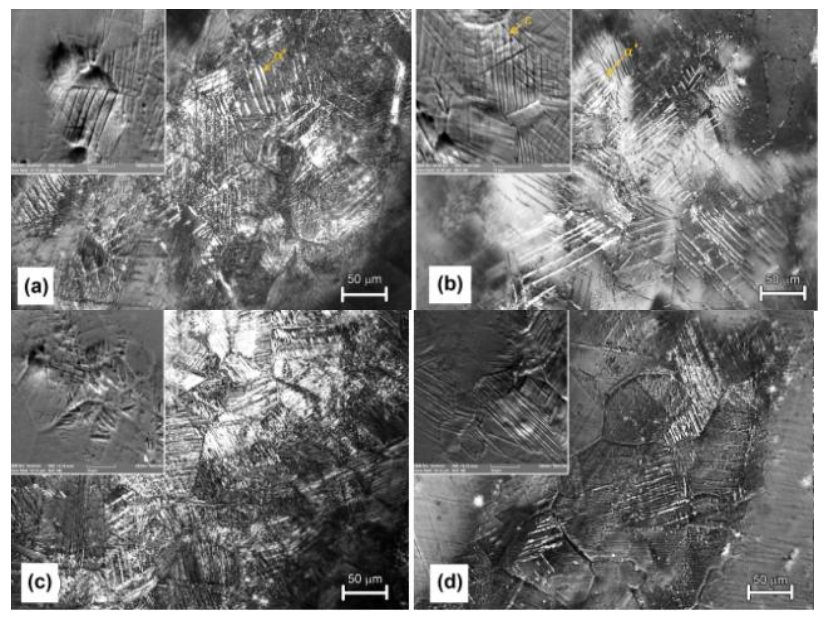

Figure 2. Representative optical micrographs with SEM insets of 0_MA specimens; (a) solution treated at $973 \mathrm{~K}$; (b) solution treated at $973 \mathrm{~K}$ and pre-strained with $2.5 \%$; (c) solution treated at $1373 \mathrm{~K}$; (d) solution treated at $1373 \mathrm{~K}$ and prestrained with $3.8 \%$

From a morphological point of view, there is a marked difference between $\varepsilon$-hcp and $\alpha$ 'bcc martensites. The former has typical "triangular" morphology, with narrow plates that completely cross austenite grains, from one border to the other [33], while the latter forms shorter bands with lenticular shape, which do not cross austenite grains [34]. In the case of PM-Fe-Mn-Si-Cr-Ni SMAs, typical grain size was approximately $10 \mu \mathrm{m}$, which rendered the observation of martensite plates rather difficult. On the dark-field $\mathrm{OM}$ micrographs from Fig.1(a) and (b) the bands of $\alpha^{\prime}$-bcc martensite can be easily observed, in contrast to $\varepsilon$-hcp plates which were noticed only at larger magnifications, in SEM insets. The density of martensite bands is obviously larger in prestrained specimens, when comparing Fig.1(b) with (a) for 973 K-solution treatment and Fig.1(c) with (d) for 1373 K-solution treatment. Therefore, a certain amount of stress-induced martensite was formed after pre-straining. On the other hand, from a morphological point of view, no obvious differences can be observed between the specimens which were solution treated to different temperatures.

Figs. 3 and 4 illustrate micrographs similar to Fig.1, but corresponding to the specimens 10_MA and 20_MA, respectively.

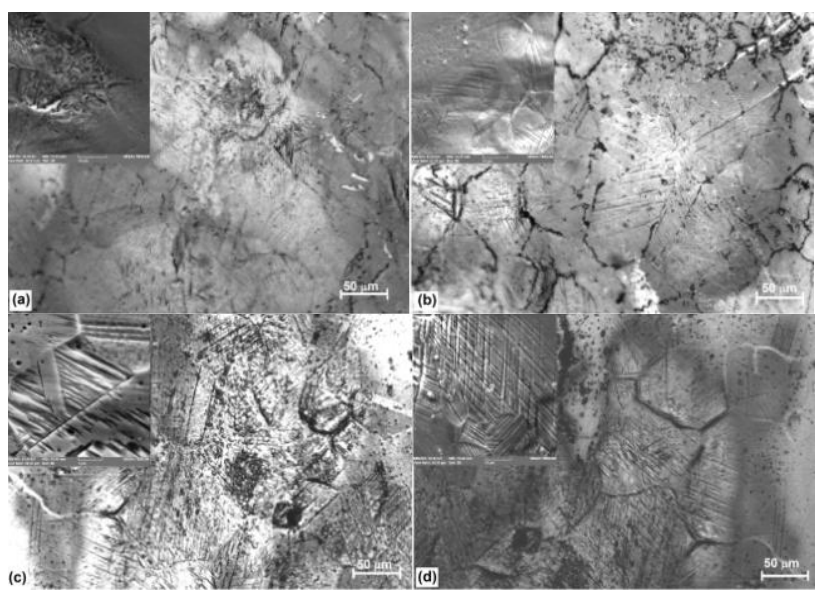

Figure 3. Representative optical micrographs with SEM insets of 10_MA specimens; (a) solution treated at $973 \mathrm{~K}$ and prestrained with $2.3 \%$; (b) solution treated at $973 \mathrm{~K}$ and prestrained with $3.5 \%$; (c) solution treated at $1373 \mathrm{~K}$ and prestrained with $1.5 \%$; (d) solution treated at $1373 \mathrm{~K}$ and prestrained with $3.1 \%$

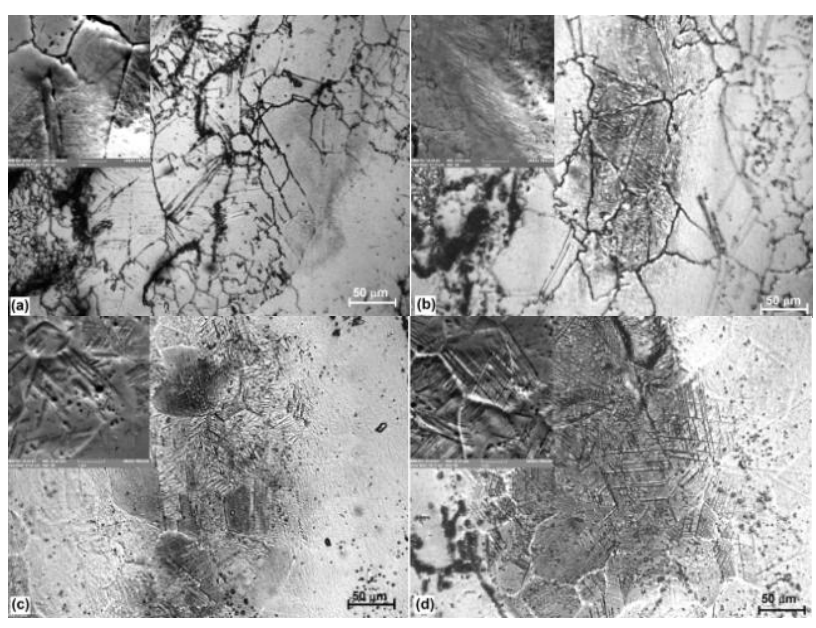

Figure 4. Representative optical micrographs with SEM insets of 20 MA specimens; (a) solution treated at $973 \mathrm{~K}$; (b) solution treated at $973 \mathrm{~K}$ and pre-strained with $1.9 \%$; (c) solution treated at $1373 \mathrm{~K}$; (d) solution treated at $1373 \mathrm{~K}$ and prestrained with $3.4 \%$

When comparing the micrographs of the specimens with increasing fractions of MA'd powders, it can be observed that martensite plates have the tendency to become finer. In addition, pre-straining caused an obvious increase of the number of martensite plates which can be ascribed to $\varepsilon$-hcp. 
The above observations were confirmed by XRD results. Most of the solution treated specimens revealed marked amounts of $\alpha^{\prime}$-bcc martensite in initial state, before pre-straining. After pre-straining, the amount of $\varepsilon$ hcp martensite tends to increase. A representative example of phase evolution tendencies, is illustrated in Fig.5, corresponding to the specimens which were solution treated at $1273 \mathrm{~K}$.
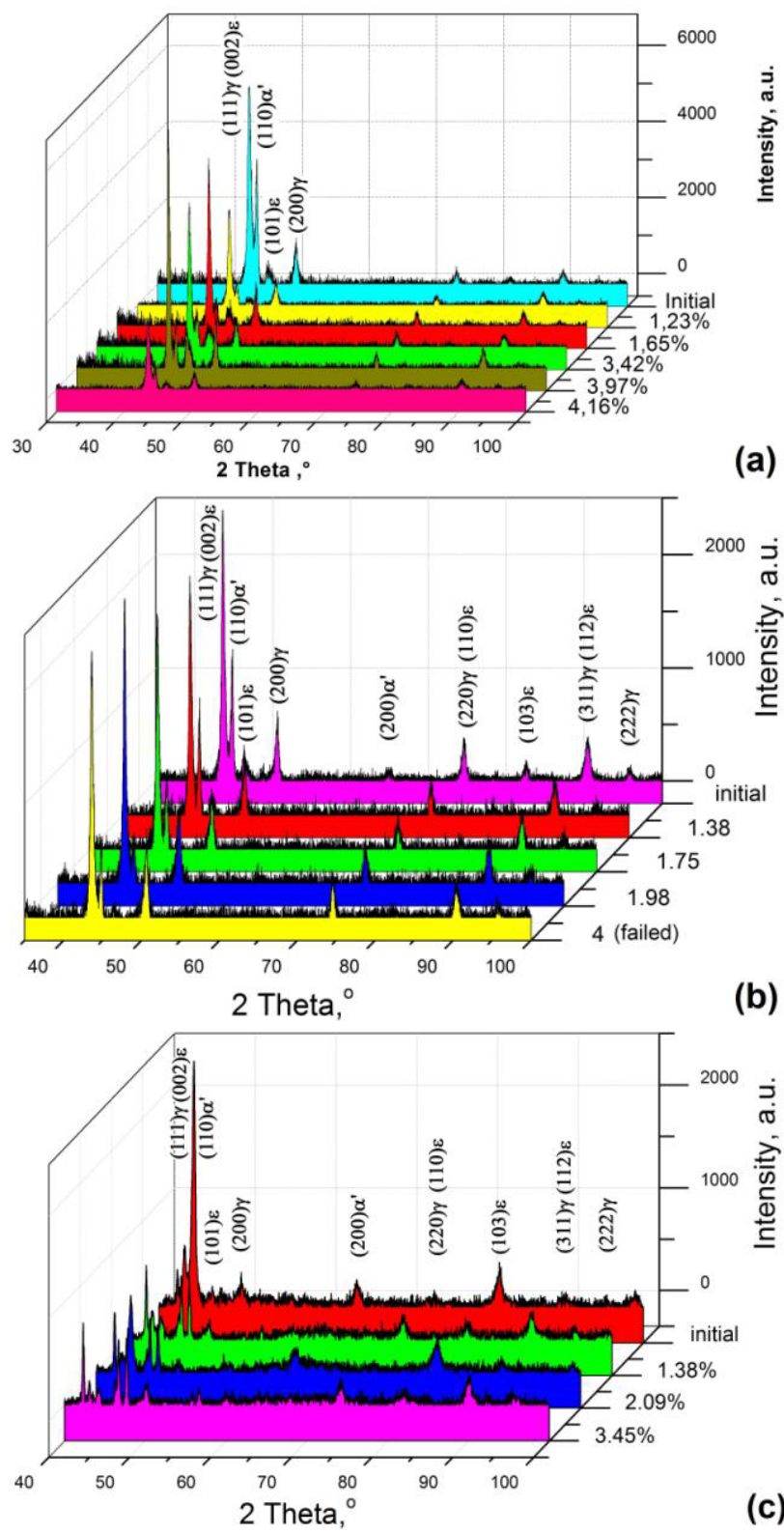

Figure 5. Characteristic XRD patterns of the specimens which were solution treated at $1273 \mathrm{~K}$, in initial and pre-strained conditions: (a) $0 \_$MA; (b) $10 \_$MA; (c) 20 MA

The diffraction maxima of XRD patterns were identified based on the crystallographic parameters of the unit cells of: (i) $\varepsilon-h c p, a_{\varepsilon}=0.254 \mathrm{~nm}$ and $\mathrm{c}_{\varepsilon}=0.4 \mathrm{~nm}$ and (ii) $\alpha^{\prime}$-bcc martensites, $a_{\alpha}{ }^{\prime}=0.287 \mathrm{~nm}$, as well as (iii) $\gamma$ fcc austenite, $a_{\gamma}=0.36 \mathrm{~nm}[35,36]$. Using the ratios between the intensities of non-overlapping peaks, $(110)_{\alpha}$, $(101)_{\varepsilon},(200)_{\gamma},(200)_{\alpha},(103)_{\varepsilon}$ and $(222)_{\gamma}$, semi-quantitative analysis [37] was done, as summarized in Table 1.
Table 1. Semi-quantitative structural analysis based on XRD patterns

\begin{tabular}{|c|c|c|c|c|c|}
\hline \multirow{2}{*}{$\begin{array}{c}\text { MA } \\
\text { fraction }\end{array}$} & \multirow{2}{*}{\begin{tabular}{|c|} 
Solution \\
treatment
\end{tabular}} & \multirow{2}{*}{$\frac{\text { Pre-strain }}{\%}$} & \multicolumn{2}{|c|}{$\mid \varepsilon$-hcp $\alpha^{\prime}-\mathrm{bcc}$} & $\gamma$-fcc \\
\hline & & & $\%$ & $\%$ & $\%$ \\
\hline \multirow{30}{*}{ 0_MA } & \multirow{6}{*}{$973 \mathrm{~K}$} & 0.00 & 6.1 & 17.8 & 76.0 \\
\hline & & 0.70 & 6.0 & 17.3 & 76.7 \\
\hline & & 1.22 & 6.1 & 29.7 & 64.2 \\
\hline & & 1.38 & 3.6 & 5.1 & 91.3 \\
\hline & & 2.00 & 6.3 & 34.4 & 59.3 \\
\hline & & 2.10 & 5.0 & 27.7 & 67.4 \\
\hline & \multirow{6}{*}{$1073 \mathrm{~K}$} & 0.00 & 5.2 & 34.0 & 60.8 \\
\hline & & 1.30 & 16.3 & 15.2 & 68.5 \\
\hline & & 1.70 & 12.7 & 28.8 & 58.5 \\
\hline & & 2.00 & 4.6 & 46.4 & 48.9 \\
\hline & & 2.10 & 13.1 & 36.4 & 50.4 \\
\hline & & 3.26 & 10.5 & 14.8 & 74.7 \\
\hline & \multirow{6}{*}{$1173 \mathrm{~K}$} & 0.00 & 4.7 & 51.9 & 43.4 \\
\hline & & 1.63 & 6.5 & 48.2 & 45.3 \\
\hline & & 1.67 & 11.8 & 15.5 & 72.7 \\
\hline & & 1.83 & 10.2 & 16.8 & 73.0 \\
\hline & & 1.95 & 8.0 & 21.4 & 70.6 \\
\hline & & 3.36 & 7.1 & 17.4 & 75.5 \\
\hline & \multirow{6}{*}{$1273 \mathrm{~K}$} & 0.00 & 6.1 & 31.8 & 62.2 \\
\hline & & 1.23 & 5.5 & 15.2 & 79.3 \\
\hline & & 1.65 & 9.9 & 10.8 & 79.4 \\
\hline & & 3.42 & 10.4 & 16.6 & 73.0 \\
\hline & & 3.97 & 10.7 & 13.3 & 76.0 \\
\hline & & 4.16 & 7.2 & 17.4 & 75.4 \\
\hline & \multirow{6}{*}{$1373 \mathrm{~K}$} & 0.00 & 2.7 & 42.2 & 55.1 \\
\hline & & 1.10 & 33.4 & 10.9 & 55.7 \\
\hline & & 1.46 & 10.4 & 13.2 & 76.4 \\
\hline & & 1.97 & 5.4 & 30.5 & 64.1 \\
\hline & & 2.05 & 5.3 & 18.1 & 76.6 \\
\hline & & 3.81 & 7.2 & 17.4 & 75.4 \\
\hline \multirow{25}{*}{ 10_MA } & \multirow{5}{*}{$973 \mathrm{~K}$} & 0.00 & 7.94 & 53.50 & 38.56 \\
\hline & & 1.47 & 14.02 & 56.37 & 29.60 \\
\hline & & 2.37 & 22.76 & 53.58 & 23.66 \\
\hline & & 3.55 & 12.37 & 45.84 & 41.79 \\
\hline & & 4 (failed) & 14.36 & 42.83 & 42.81 \\
\hline & \multirow{5}{*}{$1073 \mathrm{~K}$} & 0.00 & 30.32 & 37.82 & 31.86 \\
\hline & & 1.98 & 20.66 & 42.28 & 37.06 \\
\hline & & 2.15 & 14.88 & 36.13 & 48.98 \\
\hline & & 2.39 & 13.97 & 57.72 & 28.31 \\
\hline & & 4 (failed) & 23.80 & 29.35 & 46.85 \\
\hline & & 0.00 & 15.46 & 56.24 & 28.29 \\
\hline & & 1.53 & 8.30 & 46.43 & 45.27 \\
\hline & $1173 \mathrm{~K}$ & 2.74 & 15.98 & 41.89 & 42.13 \\
\hline & & 3 (failed) & \begin{tabular}{|l|}
8.39 \\
\end{tabular} & 58.01 & 33.61 \\
\hline & & 4 (failed) & 13.60 & 19.12 & 67.28 \\
\hline & & 0.00 & 19.19 & 50.41 & 30.40 \\
\hline & & 1.38 & 13.44 & 51.64 & 34.92 \\
\hline & $1273 \mathrm{~K}$ & 1.75 & 18.05 & 41.93 & 40.03 \\
\hline & & 1.98 & 5.66 & 32.88 & 61.47 \\
\hline & & 4 (failed) & 6.36 & 40.44 & 53.20 \\
\hline & & 0.00 & 11.00 & 59.19 & 29.81 \\
\hline & & 1.52 & 11.15 & 53.11 & 35.74 \\
\hline & $1373 \mathrm{~K}$ & 2.48 & 4.24 & 79.15 & 16.61 \\
\hline & & 3.08 & 8.58 & 51.90 & 39.53 \\
\hline & & 3.1 & 4.90 & 59.23 & 35.86 \\
\hline & & 0.00 & 11.67 & 79.47 & 8.86 \\
\hline & & 1,38 & 20,33 & 42,45 & 37,22 \\
\hline & $12 / 3 \mathrm{~K}$ & 2,09 & 24,36 & 67,04 & 8,61 \\
\hline & & 3,45 & 24,70 & 24,54 & 50,76 \\
\hline 20_MA & & 0,00 & 19,71 & 29,89 & 50,40 \\
\hline & & 1,46 & 30,35 & 58,44 & 11,21 \\
\hline & $13 \%$ & 2,28 & 64,81 & 24,79 & 10,40 \\
\hline & & 3,09 & 45,18 & 46,72 & 8,10 \\
\hline
\end{tabular}


When analysing data scattering plots, performed with ORIGIN software, large variations were observed on the amounts of the three phases. This fact does not allow getting a sound conclusion on the general tendencies of phase amount variation with solution treatment temperature and pre-straining degree. On the other hand, with increasing the fraction of MA'd powders, obvious increasing tendencies of $\alpha^{\prime}$-martensite amount were noticed, accompanied by the decrease of $\gamma$-austenite.

The mechanical response of the two types of martensite, $\alpha$ '-bcc and $\varepsilon$-hcp, was further investigated during heating, by DMA, aiming to emphasize the changes accompanying their reversion to austenite. For comparison reasons, Fig.6 shows the DMA thermograms of the same specimens, solution treated at $1273 \mathrm{~K}$, for which XRD patterns were shown in Fig.5.

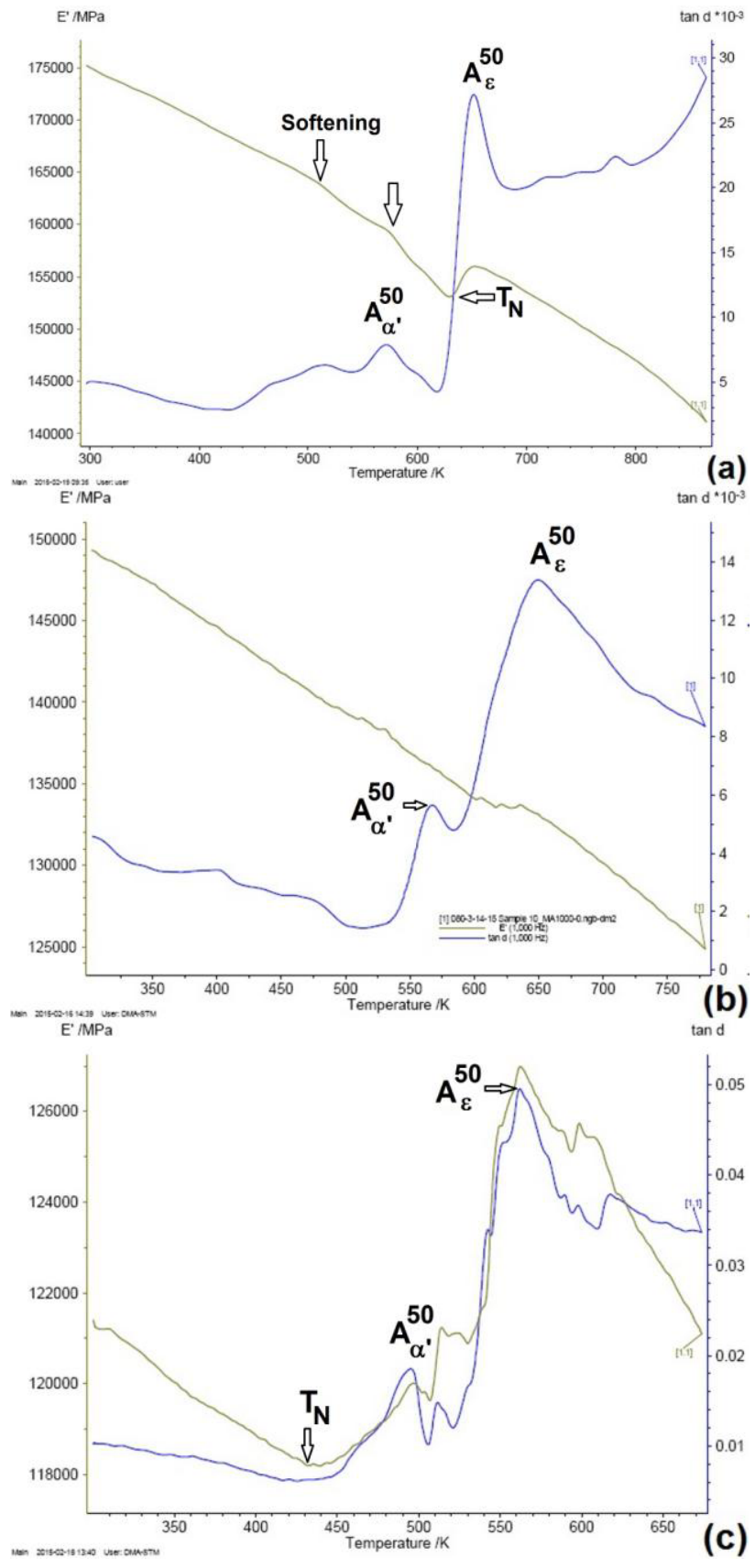

Figure 6. Typical DMA thermograms of the solution treated specimens at $1273 \mathrm{~K}$ : (a) 0_MA; (b) 10_MA; (c) 20_MA.
It is well known that martensite reversion to austenite, during heating, is accompanied, at $\mathrm{Fe}-\mathrm{Mn}-\mathrm{Si}$ based SMAs, by a local drop in storage modulus (E') since martensite is harder than austenite [38]. Consequently, two portions of "modulus softening", during heating [39], were identified by arrows in Fig.6(a). In addition, martensite reversion to austenite has always been associated with a local maximum of internal friction (tan ס) [40] but there is a temperature shift between the starting point of modulus softening (decrease) and the beginning of internal friction peak [41]. In PM-MA'd FeMn-Si-Cr-Ni SMAs, where large amounts of $\alpha^{\prime}$-bcc martensite were thermally induced, when two $\tan \delta$ maxima are noticed, during heating, the former was attributed to $\alpha^{\prime}$-bcc $\rightarrow \gamma$-fcc and the latter to the $\varepsilon$-hcp $\rightarrow$ $\gamma$-fcc transformations, [42]. In Fig. 6 the two reverse martensite transitions reached the maximum at $\mathrm{A}^{50}{ }_{\alpha}$, and $\mathrm{A}_{\varepsilon}^{50}$, respectively. Another particularity of the alloys under study is the fact that $\tan \delta$ did not reach the same value, at the end of transformation, as it had before it, due to the large values of porosity degrees, ranging between $16.85 \%$ for 0 MA and $5.94 \%$ for 20_MA. Another important characteristic, of the alloys under study, is the increase of E', during heating, which can be associated with the antiferromagnetic transition of $\gamma$-fcc austenite. Its characteristic temperature (Néel) was designated as $T_{N}$ and localizes the beginning of storage modulus increase during heating [43].

When comparing the fifteen DMA thermograms of the alloys under study, it was observed that the critical temperatures $\mathrm{A}^{50}{ }_{\alpha}, \mathrm{A}^{50}{ }_{\varepsilon}$ and $\mathrm{T}_{\mathrm{N}}$ experienced rather large variation tendencies which could be caused by the above mentioned values of porosity degrees as well as by the differences in chemical composition among as blended (elemental) and MA'd powders.

\section{Summary and conclusions}

Fifteen sets of Fe-14Mn-6Si-9Cr-5Ni SMA specimens were obtained by powder metallurgy, with three fractions of mechanically alloyed powders (0, 10 and 20 vol. \%) which were solution treated to five temperatures $(973 \mathrm{~K}$, $1073 \mathrm{~K}, \ldots, 1373 \mathrm{~K}$ ). Each set of specimens was prestrained with various deformation degrees up to $4 \%$, with the aim to stress-induced martensite.

By optical and scanning electron microscopy the formation of thermally induced $\alpha^{\prime}$-bcc martensite was revealed, besides $\varepsilon$-hcp, as a particularity of these PMMA'd alloys. Martensite plates became finer with the increase of MA'd fraction. The presence of both martensites and $\gamma$-fcc austenite was confirmed on XRD patterns.

With increasing the fraction of MA'd powders the amount of $\alpha^{\prime}$-bcc martensite experienced a global increasing tendency on behalf of the amount of $\gamma$-fcc austenite.

The reversions to austenite of the two martensites, during heating, were emphasized by DMA, by means of two different internal friction maxima. The antiferromagnetic-paramangetic transition was accompanied by an increase of storage modulus, on heating. 


\section{Acknowledgements}

This research work was supported by UEFISCDI through project code PN.IIPT-PCE- 2012-4-0033, Contract 13/2013.

\section{References}

1. A. Sato, E. Chishima, K. Soma and T. Mori, Acta Metall., 30(6), 1177-1183 (1982),

2. A. Sato, K. Soma and T. Mori, Acta Metall., 30(10), 1901-1907, (1982)

3. A. Sato, E. Chishima, Y. Yamaji and T. Mori, Acta Metall., 32(4), 539-547, (1984)

4. M. Murakami, H. Suzuki and Y. Nakamura, Trans. ISIJ, 27, B-87, (1987)

5. M. Murakami, H. Otsuka, H. Suzuki and S. Matsuda, Trans. ISIJ, 27, B-88, (1987)

6. M. Murakami, H. Otsuka and S. Matsuda, Trans. ISIJ, 27, B-89, (1987)

7. H. Otsuka, H. Yamada, T. Maruyama, H.; Tanahashi, S.; Matsuda, M. Murakami, ISIJ Int, 30, 674-679, (1990)

8. Y. Moriya, H. Kimura, S. Ishizaki, S. Hashizume, S. Suzuki, H. Suzuki, T. Sampei, J. Phys. IV France 01, 433-437, (1991)

9. T. Maki, in: Otsuka, K., Wayman, C.M. (Eds.), Shape Memory Materials, University Press, Cambridge, 117-132, (1998)

10. D. Dunne, in Pereloma E and Edmonds DV (Eds.), Diffusionless transformations, high strength steels, modelling and advanced analytical techniques, Vol 2. Woodhead Publishing, 83-125, (2012)

11. G. J. Arruda, V. T. L. Buono, M. S. Andrade, Mater. Sci. Eng. A, 273-275, 528-532 (1999)

12. Y.H. Wen, N. Li, and L.R. Xiong, Mater. Sci. Eng. A, 407, 31-35, (2005)

13. H. Berns and W. Theisen, Ferrous Materials. Steel and Cast Iron, 190-198, 378-380, 397-399, Springer, (2008)

14. Z. Zhang, R. Sandström, K. Frisk and A. Salwen, Powder Technol., 137, 139-147, (2003)

15. T. Liu, H.Y. Liu, Z.T. Zhao, R.Z. Ma, T.D. Hu, and Y.N. Xie, Mater. Sci. Eng. A, 271, 8-13, (1999)

16. Y. Kim, Y.-B. Song, S. H. Lee, J. Alloy. Compd., 637, 234-241, (2015)

17. T. Saito, K. Gąska, A. Takasaki and C. Kapusta, J. Mekanikal, 30, 62-67, (2010)

18. R. Amini, A. Shamsipoor, M. Ghaffari, M. Alizadeh, A. K. Okyay, Mater. Charact., 84, 169-174, (2013)

19. T. Saito, C. Kapusta, A. Takasaki, Mat. Sci. Eng. A, 592, 88-94, (2014)

20. Z. Xu, M. A. Hodgson, P. Cao, Mat. Sci. Eng. A, 630, 116-124, (2015)
21. L. G. Bujoreanu, S. Stanciu, B. Özkal, R. I. Comăneci and M. Meyer, ESOMAT, 05003, (2009)

22. B. Pricop, U. Söyler, R.I. Comăneci, B. Özkal, and L.G. Bujoreanu, Phys. Procedia, 10, 125-131, (2010)

23. B. Pricop, U. Söyler, N.M. Lohan, B. Özkal, D. Chicet, A. David and L.-G. Bujoreanu, Optoelectron. Adv. Mater., 5(5), 555-561, (2011)

24. B. Pricop, U. Söyler, N.M.Lohan, B. Özkal, L.G. Bujoreanu, D. Chicet, C. Munteanu, J. Mater. Eng. Perform., 21(11), 2407-2416, (2012)

25. B. Pricop, U. Söyler, B. Özkal, N. M. Lohan, A. L. Paraschiv, M. G. Suru and L. G. Bujoreanu, Mater. Sci. Forum, 738-739, 237-241, (2013)

26. B. Pricop, B. Özkal, U. Söyler, J. Van Humbeeck, N. M. Lohan, M. G. Suru and L. G. Bujoreanu, Optoelectron. Adv. Mat., 8(3-4), 247 - 250, (2014)

27. A. U. Söyler, B. Özkal and L. G. Bujoreanu, J. Mater. Eng. Perform., 2014, 23(7), 2357-2361, (2014)

28. L.G. Bujoreanu, S. Stanciu, R.I. Comăneci, M. Meyer, V. Dia, and C. Lohan, J. Mater. Eng. Perform., 18(5-6), 500-505, (2009)

29. A. U. Söyler, B. Özkal and L.G. Bujoreanu, TMS Suppl. Proc., 1, 577-583, (2011)

30. A. U. Söyler, B. Özkal and L.G. Bujoreanu, TMS Suppl. Proc., 3, 785-792, (2010).

31. H. A. Bowman and R. M. Schoonover, J Res Natl Inst Stan- C. Eng. Instr., 71(3), 179-198, (1967)

32. V. Dia, U. Söyler, B. Pricop, B. Özkal and L.-G. Bujoreanu: 15th International Metallurgy and Materials Congress, IMMC 2010, 11-13 November 2010, Istanbul, Turkey, 1071-1075, (2010).

33. P. K. Mukhopadhyay, M. Karmakar, B. R. Kanth, S. N. Kaul, J. Alloy Compd., 577S, S119-S122, (2013).

34. S. Kajiwara, Mater. Sci. Eng. A, 273-275, 67-88, (1999).

35. B. C. Maji, K. Madangopal, V. V. Rama Rao, Metall. Mater. Trans., 34A, 1029-1042, (2003).

36. T. Kirindi, E. Güler, M. Dikici, J. Alloy. Compd., 433, 202-206, (2007).

37. T. Sawaguchi, L. G. Bujoreanu, T. Kikuchi, K. Ogawa, F. Yin, ISIJ Int., 48(1), 99-106, (2008).

38. V. G. Gavriljuk, P. G. Yakovenko, K. Ullakko, Scripta Mater., 38, 931-935, (1998).

39. J. F. Wan, S. P. Chen, T. Y. Hsu, Y. N. Huang, Mat. Sci. Eng. A, 438-440, 887-890, (2006).

40. X. Wu, T. Y. Hsu, Mater. Char., 45, 137-142, (2000).

41. Z. C. Zhou, Mat. Sci. Eng. A, 438-440, 336-338, (2006).

42. T. S. Chou, H. C. Lin, K. M. Lin, S. K. Wu, Scripta Mater., 42, 445-450, (2000).

43. J. Van Humbeeck, J. Stoiber, L. Delaey and R. Gotthardt, Z. Metallkd., 86(3), 176-183, (1995). 